\title{
Phytotoxicological Assessment of Two Backwater Wetlands in Kannamaly, Ernakulam Using Aquatic Macrophyte - Spirodela Polyrhiza.
}

Anil Loveson* and Rajathy Sivalingam

School of Environmental Studies, Cochin University of Science and Technology, Kerala, India

\begin{abstract}
In the current study, the duckweed aquatic macrophyte Spirodela polyrrhiza was employed for assessing the toxicity of two backwater wetlands in the Kannamaly, Chellanam panchayath, Ernakulam district, Kerala, South India. The assessments were made according to OECD guidelines for testing (2006). The studies involve study of growth parameters, Growth Index, Biomass and changes in productivity. The water samples were collected from two different wetland sites at the same time. The spirodela plants were introduced into several dilutions of wetland water samples. The parameters were measured after 7 days of exposure. All samples except control affected all parameters. The results of this study emphasize the significance of duckweeds as standard and reliable testing material for biological parameters in polluted aquatic ecosystem.
\end{abstract}

Keywords: Growth inhibition; Spirodela polyrrhiza; Growth Index; Macrophyte; Duckweed

\section{Introduction}

Wetlands support a wide array of flora and fauna and deliver many ecological, climatic and societal functions. Scientists often refer to wetlands as the" kidneys" of the earth. Kerala is well known for its wetlands. The Kerala coast is bordered by 29-backwaters running parallel to the shoreline. The water quality of these backwaters is deteriorating due to population explosion, rapid industrialization, silting, tourism and agricultural activities. Effluents from industries are major cause of pollution in coastal area. The waste water/effluents from seafood processing plant have high organic content. The effluents from Shrimp processing plants locates at Kannamaly, Chellanam panchayath, Ernakulam district directly discharge the waste water to the neighboring water bodies. Apart from raising the BOD at immediate vicinity, limited effluents do not cause any severe damage to the system. But at high levels, often cause severe pollution and adversely affect the aquatic flora and fauna. Standardised ecotoxicity test methods frequently uses duckweed species Spirodela polyrrhiza due to their advantages such as rapid vegetative propagation, sensitivity to toxicants, easy culturing under axenic conditions [1]. Spirodela polyrrhiza has tolerance to moderate saline conditions. Duckweeds are salinity tolerant, adapt with time to high salinity, remove salinity, and have a potential for desalination in agricultural detention ponds [2].

\section{Objectives}

The objective of current study to assess the toxicity of water from two wetlands by standard testing procedure that includes growth analysis and photosynthetic pigment analysis.

\section{Materials and Methods}

Duckweed Spirodela polyrrhiza were obtained from an unpolluted natural pond near Fort Kochi, Kerala, India. It is a floating aquatic macrophyte belonging to the family Lemnaceae and can be found worldwide on the surface of fresh and brackish waters [3]. The duckweeds .are among the most standardized test organisms in aquatic ecotoxicology [4-7]. One sample (Wetland 1) was collected approximately 50 meters south of the Kannamaly pilgrim centre and close to India Seafoods Factory, at a location approximately Lat $9.8704^{\circ} \mathrm{N}$ and Long $76.2665^{\circ} \mathrm{E}$ ) (Figure 1).
The second sample (Wetland 2) was collected from the wetlands south to the " wetland I area, approximately $1.8 \mathrm{~km}$ away and located at Lat $9.8612^{\circ} \mathrm{N}$ Long $76.2642^{\circ} \mathrm{E}$ ) (Figure 2).

Wetland water samples collected from two sites were analysed according to APHA standards [8]. Metals were analysed using AAS. Test solutions were prepared by diluting water samples of wetland 1 and 2 with distilled water. The solutions were prepared in $100 \%, 50 \%$, $25 \%, 10 \%, 5 \%$ and $0.5 \%$ concentrations of wetland water plus a control (water taken from an unpolluted site near Kumbalangi, $3 \mathrm{~km}$ away from Kannamaly. After seven days of exposure, plants were harvested, washed with double distilled water, blotted and used for the study of various parameters. The parameters include study of vegetative characters, growth parameters and study photosynthetic pigments. All the tests were conducted in six replicates.

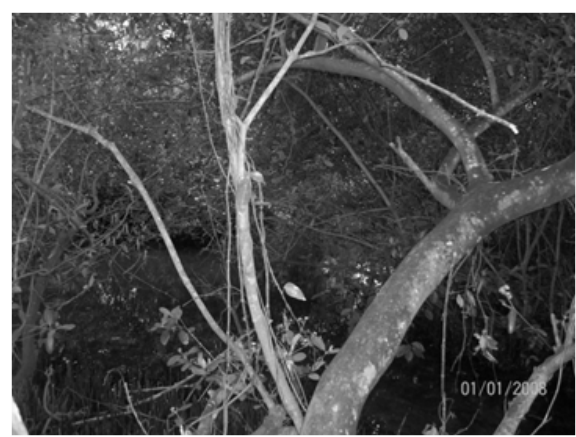

Figure 1: One sample (Wetland 1) was collected approximately 50 metres south of the Kannamaly pilgrim centre and close to India Seafoods Factory.

*Corresponding author: Anil Loveson, School of Environmental Studies, Cochin University of Science and Technology, Kerala, India, Tel. 9447306606; E-mail: anil.cusat@gmail.com

Received May 28, 2013; Accepted June 28, 2013; Published July 01, 2013

Citation: Loveson A, Sivalingam R (2013) Phytotoxicological Assessment of Two Backwater Wetlands in Kannamaly, Ernakulam Using Aquatic Macrophyte Spirodela Polyrhiza. J Environ Anal Toxicol 3: 180. doi:10.4172/2161-0525.1000180

Copyright: @ 2013 Loveson A, et al. This is an open-access article distributed under the terms of the Creative Commons Attribution License, which permits unrestricted use, distribution, and reproduction in any medium, provided the original author and source are credited. 


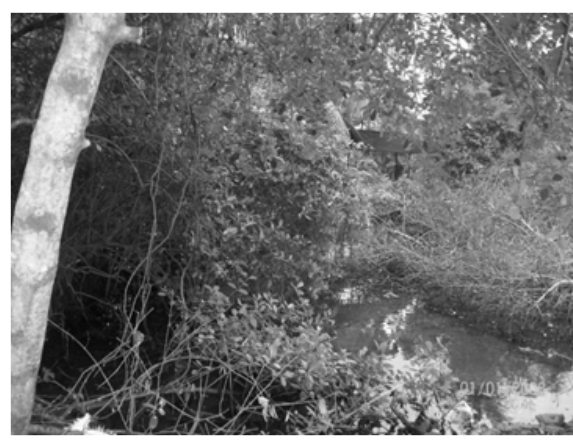

Figure 2: The second sample (Wetland 2) was collected from the wetlands south to the wetland I area, approximately $1.8 \mathrm{~km}$ away.

\section{Analysis of Parameters}

\section{Physio chemical analysis of wetland water}

\section{Study of growth parameters:}

1.a. Dry weight: All colonies are collected from each of the test vessels and rinsed with distilled or deionised water. They are blotted to remove excess water and then dried at $60^{\circ} \mathrm{C}$ to a constant weight. Any root fragments should be included. The dry weight should be expressed to an accuracy of at least $0.1 \mathrm{mg}$.

1.b. Fresh weight: All colonies are transferred to pre-weighed plastic tubes with small $(1 \mathrm{~mm})$ holes in the rounded bottoms. The tubes are then centrifuged at $3000 \mathrm{rpm}$ for 10 minutes at room temperature. Tubes, containing the now dried colonies, are re-weighed and the fresh weight is calculated by subtracting the weight of the empty tube.

1.c. Dry weight-Fresh weight ratio can be determined from above estimations. The plant growth index was calculated as follows

$$
\text { Growth Index }=\frac{\text { Biomass }(t=7 \text { days })}{\text { Biomass }(t=0)}
$$

1.d. Doubling time: To determine the doubling time (Td) of frond number and adherence to this validity criterion by the study, the following formula is used with data obtained from the control vessels:

$\mathrm{Td}=\ln 2 / \mu$

Where $\mu$ is the average specific growth rate.

1. e. Average specific growth rate: this response variable is calculated on the basis of changes in the logarithms of frond numbers, and in addition, on the basis of changes in the logarithms of another measurement parameter (total frond area, dry weight or fresh weight) over time (expressed per day) in the controls and each treatment group. It is sometimes referred to as relative growth rate. The average specific growth rate for a specific period is calculated as the logarithmic increase in the growth variables -frond numbers and one other measurement variable (total frond area, dry weight or fresh weight) - using the formula below for each replicate of control and treatments:

$$
\mu_{i-j}=\frac{\ln \left(N_{j}\right)-\ln \left(N_{i}\right)}{t}
$$

where:

$\mu_{i-j}:$ average specific growth rate from time $i$ to $j$

$\mathrm{N}_{\mathrm{i}}$ : measurement variable in the test or control vessel at time $\mathrm{i}$

$\mathrm{N}_{\mathrm{j}}$ : measurement variable in the test or control vessel at time $\mathrm{j}$ t: time period from $i$ to $j$

1.f. Percentage of growth inhibition: Percent inhibition of growth rate (Ir) may then be calculated for each test concentration according to the following formula

$\% \operatorname{Ir}=\frac{(\mu C-\mu T)}{\mu C} \times 100$

where:

$\%$ Ir: percent inhibition in average specific growth rate

$\mu \mathrm{C}$ : mean value for $\mu$ in the control

$\mu \mathrm{T}$ : mean value for $\mu$ in the treatment group

\section{Estimation of photosynthetic pigments}

The chlorophyll estimation is an important study parameter for the estimation of impact of pollution on photosynthetic activity. About $200 \mathrm{mg}$ of treated plants were weighed. This is taken in a mortar with $5 \mathrm{mlof} 90 \%$ acetone and $1 \mathrm{ml}$ of Magnesium carbonate. It is then ground thoroughly with pestle. This is then kept at $4^{\circ} \mathrm{C}$ for 4 hours for the pigments to elute. The solution is then centrifuged at $2500 \mathrm{rpm}$ for 15 minutes. The extract is then decanted to a volumetric flask and the volume is made up to $50 \mathrm{ml}$ with $90 \%$ acetone. The absorbance at $750,663,645,510$ and 480 were measured in the spectrophotometric analysis using Hitachi-U-2000 spectrophotometer.

\section{Statistical analysis}

Analysis of variance for each test was conducted using STATISTICA software (One way Anova). The significant difference between treatments were determined by Duncan's multiple range test $(\mathrm{P}<0.05)$. Each test was conducted in six replicates.

\section{Results and Discussions}

Physiochemical properties of water from both wetlands are given in Table 1. The values of BOD, Nitrate, phosphate, Ammonia, TDS, TSS Turbidity and heavy metals $\mathrm{Cu}, \mathrm{Pb}, \mathrm{Zn}$ and $\mathrm{Cd}$ were significantly high in wetland 1 in comparison to the control.

\begin{tabular}{|r|l|r|r|r|}
\hline SI.No & Parameter (Unit) & $\begin{array}{c}\text { Control } \\
\text { wetland }\end{array}$ & Wetland 1 & Wetland 2 \\
\hline 1 & Temp $\left({ }^{\circ} \mathrm{C}\right)$ & 28.8 & 29.1 & 28.8 \\
\hline 2 & Conductivity $(\mathrm{mS})$ & 1.67 & 4.1 & 2.3 \\
\hline 2 & $\mathrm{pH}$ & 7.9 & 8.2 & 7.8 \\
\hline 3 & Salinity $(\mathrm{ppt})$ & 1.8 & 1.8 & 1.8 \\
\hline 4 & DO(mg O2/L) & 5 & 2.65 & 3.2 \\
\hline 5 & BOD(mg O $/ \mathrm{L})$ & 8 & 112 & 12.24 \\
\hline 6 & Nitrate(mg/L) & 45 & 12.28 & 0.91 \\
\hline 7 & Phosphate(mg/L) & 6.2 & 14.42 & 1.57 \\
\hline 8 & Ammonia & 1.2 & 28.09 & 0.75 \\
\hline 9 & TDS & 2100 & 2811 & 2220 \\
\hline 10 & TSS & 112 & 55.42 & 24.89 \\
\hline 11 & Turbidity & 11 & 413.2 & 13.8 \\
\hline 12 & Cu(mg/L) & 2.4 & 2.43 & 2.2 \\
\hline 13 & Pb(mg/L) & 1 & 3.71 & 2.68 \\
\hline 14 & Zn(mg/L) & 3.2 & 112.21 & 23.2 \\
\hline 15 & Cd(mg/L) & not detected & 2.33 & 0.47 \\
\hline
\end{tabular}

Table 1: Results of physio chemical analysis of Wetland 1 and 2 water before exposure. Each values are means of triplicates. The significant difference between treatments is $\mathrm{P}<0.05$ 
Citation: Loveson A, Sivalingam R (2013) Phytotoxicological Assessment of Two Backwater Wetlands in Kannamaly, Ernakulam Using Aquatic Macrophyte - Spirodela Polyrhiza. J Environ Anal Toxicol 3: 180. doi:10.4172/2161-0525.1000180

Page 3 of 5

Duckweeds show great tolerance to changes in physiochemical parameters of water. The growth rate of duckweed is favoured by organic pollutants as well as inorganic nutrients. Gopal and Chamanlal [9] reported the maximum biomass of L. perpusilla and S. polyrrhiza from roadside pools and ditches in India within an electrolyte conductivity range of $650-1000 \mu \mathrm{S} / \mathrm{cm}$.

The concept of average specific growth rate is based on the general exponential growth pattern of duckweed in non-limited cultures, where toxicity is estimated on the basis of the effects on the growth rate, without being dependent on the absolute level of the specific growth rate of the control; slope of the concentration-response curve or on test duration. The use of average specific growth rate for estimating toxicity is scientifically preferred. In the current study ASGR and frond doubling time $(\mathrm{Td})$ of the control and treatment with $0.5 \%$ and $5 \%$ concentration I WI yield the same result.WII water shows different result ASGR and $\mathrm{Td}$ remains same as control up to $25 \%$ concentration. The inhibition of growth in this concentration is negligible. As the concentration of effluent increases, all the parameters vary. For the test to be valid, the doubling time of frond number in the control must be less than 2.5 days $(60 \mathrm{~h})$ (OECD guidelines) [7]. When the frond doubling time exceeds 2.5 , the test solution is considered toxic. In the study only un dilutes $100 \%$ concentration water from wetland 1 shows $\mathrm{Td}$ values more than 2.5 , thus found to be toxic. The values are given in Table 2 .

Plant growth index were measured after 7 days of exposure with different dilutions of water from both wetlands. At $0.5 \%$ and $5 \%$ dilution GI is greater than control values in both waters. At 10\% W2 treatment shows less GI than control but W1 still has values above control which shows the water quality of W1 is better than W2. From $25 \%$ GI values shows sharp decline in both treatments. The finding is given in Table 3.

The growth index of both wetland water is similar in lowest concentration $(0.5 \%)$. From $5 \%$ dilution onwards it is quite clear that growth of Spirodela is enhanced more in wetland I. This may be due to the increase in crude protein content of duckweed however, seems to increase to a maximum of $\sim 40$ percent $\mathrm{DM}$ over the range from trace ammonia concentrations to 7-12 mg N/L [10]. Khondker, Islam and

\begin{tabular}{|c|c|c|c|c|c|}
\hline \multirow[b]{2}{*}{ Site } & Medium & Mean $\mathbf{N j}$ & Mean ASG $(\mu)$ & Td & $\%$ \\
\hline & control & 16 & 4.258 & 1.272 & 0 \\
\hline \multirow[b]{6}{*}{ Wet I } & 0.5 & 16 & 4.258 & 1.272 & 0 \\
\hline & 5 & 16 & 4.258 & 1.272 & 0 \\
\hline & 10 & 15 & 3.871 & 1.4 & 9.08 \\
\hline & 25 & 14 & 3.484 & 1.555 & 18.177 \\
\hline & 50 & 13 & 3.097 & 1.75 & 27.26 \\
\hline & 100 & 10 & 1.935 & 2.801 & 34.21 \\
\hline \multirow[b]{6}{*}{ Wet 2} & 0.5 & 16 & 4.258 & 1.272 & 0 \\
\hline & 5 & 16 & 4.258 & 1.272 & 0 \\
\hline & 10 & 16 & 4.258 & 1.272 & 0 \\
\hline & 25 & 16 & 4.258 & 1.272 & 0 \\
\hline & 50 & 15 & 3.871 & 1.4 & 9.08 \\
\hline & 100 & 15 & 3.871 & 1.4 & 9.08 \\
\hline
\end{tabular}

Table 2: ASGR, Td and Ir\% of S. polyrrhiza after 7 days of treatment with various dilutions of wetland $I$ and 2. Mean $N(i)=5$, Mean $T(j)=7$ and $T(i)=0$. Standard deviations were presented by error bars. Each value is means of six replicates. The significant difference between treatments is $\mathrm{P}<0.05$.

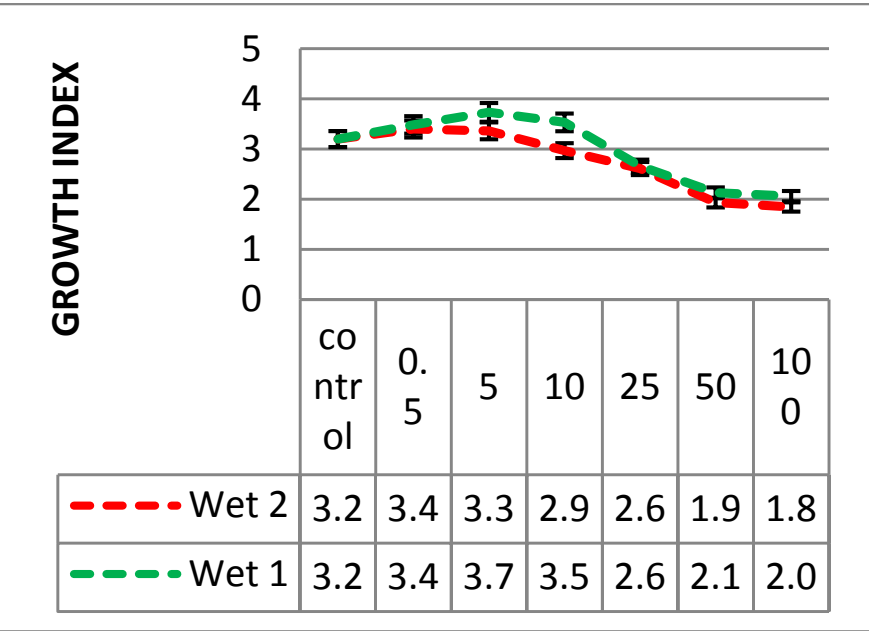

Table 3: Growth Index of Spirodela plant in different dilutions of Wetland 1 and 2 after 7 days of exposure. Standard deviations were presented by error bars. Each values are means of six replicates. The significant difference between treatments is $P<0.05$.

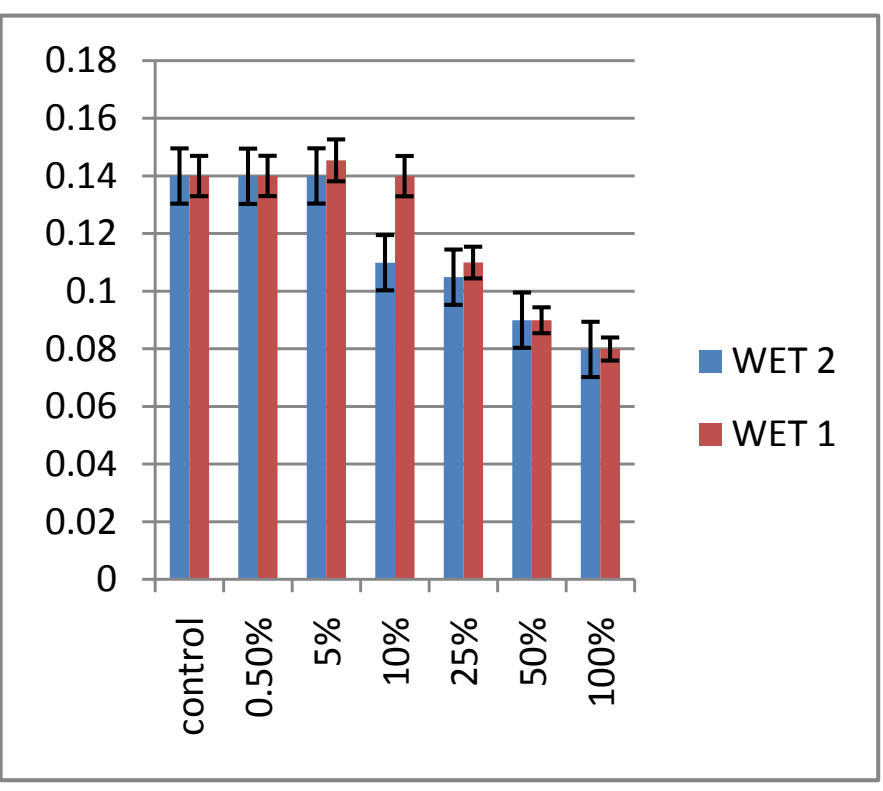

Table 4: Biomass DW/FW ratio of S. polyrrhiza after 7 days of exposure in water from Wetland 1 and 2. Standard deviations were presented by error bars. Each values are means of six replicates. The significant difference between treatments is $\mathrm{P}<0.05$.

Makhnun [11] observed that both phosphate and silicate concentrations had significant positive correlation with the biomass of L. perpusilla in Bangladesh. But at 25\% dilution GI is surprisingly similar. At extreme concentrations again GI vary. The differences in GI under different concentrations are illustrated in Table 4.

Changes in Dry weight fresh weight ratio indicate that in exposed Spirodela plants, growth retardation takes place in comparison to the control. At $0.5 \%$ concentration, the biomass yield is same as that in control. In $5 \%$ concentration of wetland 1and 2 water, slight increase in DW/FW ratio recorded in wetland 2 effluents than control. At $10 \%$ and $25 \%$ solutions, the DW/FW ratio is higher in weland water 1 in comparison with Wet 2 . But in $50 \%$ and $100 \%$ the ratio shows sharp decline. It was noted that at $50 \%$ concentration, spirodela growing in highly polluted weland 2 water yield higher FW/DW ratio than those growing in wetland 1 ( Table 5). 
Citation: Loveson A, Sivalingam R (2013) Phytotoxicological Assessment of Two Backwater Wetlands in Kannamaly, Ernakulam Using Aquatic Macrophyte - Spirodela Polyrhiza. J Environ Anal Toxicol 3: 180. doi:10.4172/2161-0525.1000180

Page 4 of 5

The decline in biomass ratio may be due the presence of excess heavy metals present in wetland. It has been shown that accumulation of heavy metals disturb the plant water status which eventually results in osmotic stress and growth reduction $[12,13]$. Water especially in wetland 2 . In wetland 1 the biomass (DW/FW ratio) percentage was 100, 100.7, 103.9, $100,78.5,64.27$, and 57.1 for dilutions $0.5,5,10,25,50$ and 100 respectively. Similarly for wetland 2 it was $100,99.9,100.07,78.4,74.9,64.2$, and 57.04 for dilutions $0.5,5,10,25,50$ and 100 respectively.

Chlorophyll and carotenoids are the central part of the energy manifestation of every green plant system and therefore, any significant alteration in their levels is likely to cause a marked effect on the entire metabolism of the plant. The productivity of plants is directly related with changes in the content of photosynthetic pigments chlorophyll a, chlorophyll $\mathrm{b}$ and Carotenoids. Industrial wastewater not only affects the chlorophyll content but the chlorophyll activity also [14-16]. In the study photosynthetic pigments may be inhibited due to metal toxicity. Industrial wastewater not only affects the chlorophyll content but the chloroplast activity also [14-16].

Duckweed leaves started to show signs of chlorosis (pigment loss) following $7 \mathrm{~d}$ exposure to surface water samples. At $50 \%$ and $100 \%$ dilutions necrosis could also seen. The Carotenoids contents are found to be less affected. At the end of 7 days of exposure $0.5 \%$ dilution of wetland 1 and 2 shows slight increase in chlorophyll a content (Hormesis) while at the same dilution and Carotenoids content remain unchanged. From 5\% to $100 \%$ all pigments shows gradual decrease in concentration. Chl $b$ degraded at a much slower rate than chl $a$ which indicates that greater damage of pollutants present in water samples on chl $a$. The loss of photosynthetic pigment content has been reported in duckweed plants following exposure to $\mathrm{Cu}, \mathrm{Pb}$ and $\mathrm{Ni}$ [17-19]. The destruction of photosynthetic pigments by heavy metals could be due to: impairment of ETC, replacement of Magnesium ions associated with chlorophyll ring, inhibition of important enzymes [20] associated with chlorophyll synthesis or peroxidation processes in chloroplast membrane lipids by reactive oxygen species [21] (Table 6).

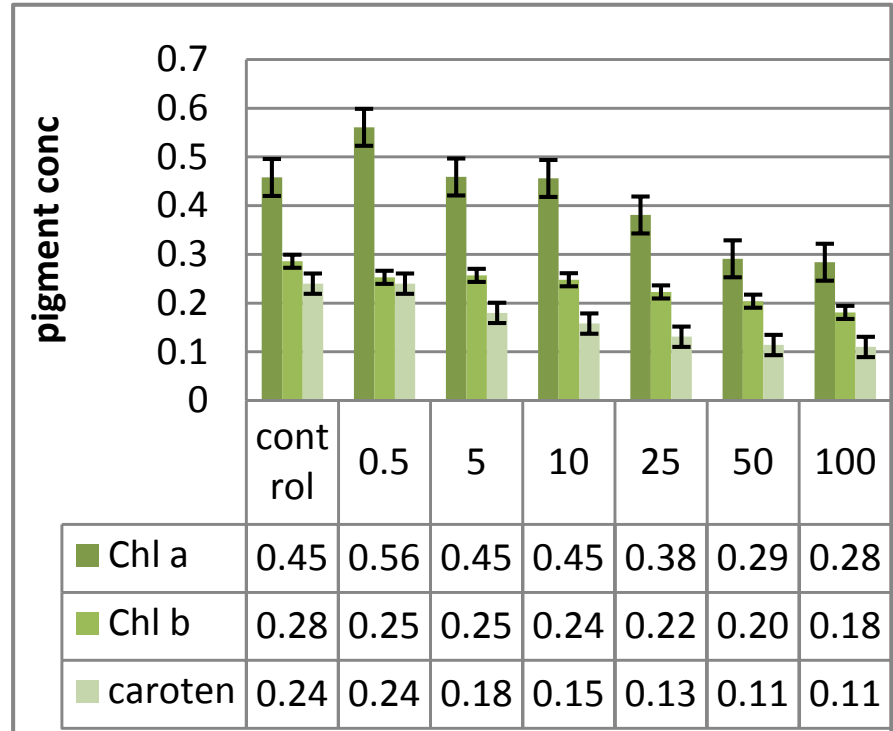

Table 5: Relative photosynthetic pigment concentrations after 7 days of exposure in different dilutions of wetland 1. Standard deviations were presented by error bars. Each values are means of six replicates. The significant difference between treatments is $\mathrm{P}<0.05$.

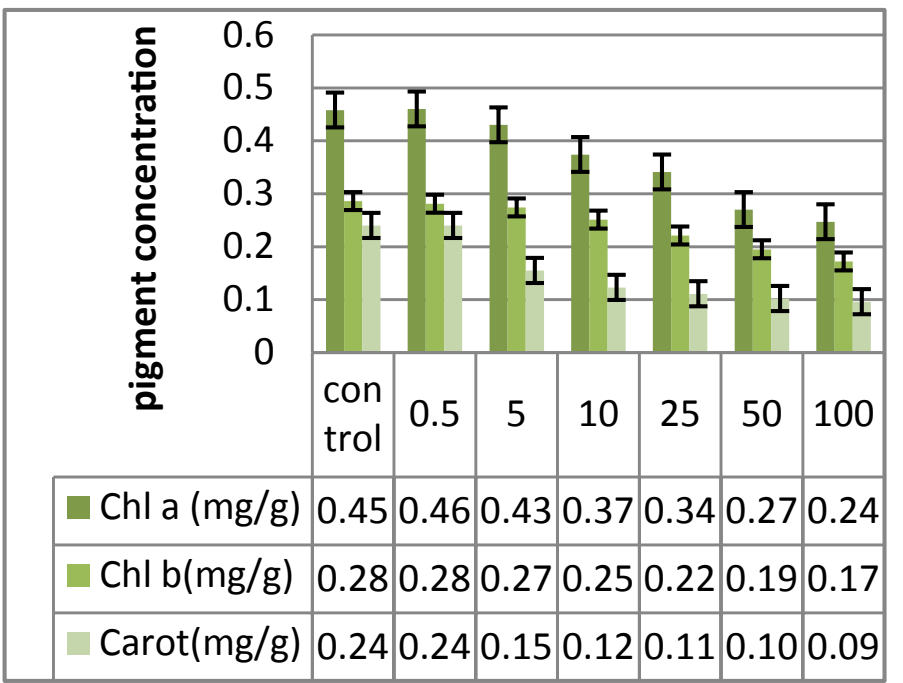

Table 6: Relative photosynthetic pigment concentrations after 7 days of exposure in different dilutions of wetland 2. Standard deviations were presented by error bars. Each values are means of six replicates. The significant difference between treatments is $\mathrm{P}<0.05$.

\section{Conclusion}

The study revealed that both welands are highly polluted. Wetland 2 has more pollutants compared with wetland 1 which is evident from the assessment of vegetative, growth and photosynthetic pigment parameters. The study also points towards the importance of conservation of wetlands in the area.

\section{Acknowledgement}

The authors are grateful to the School of Environment studies, CUSAT, for providing technical assistance to carry out the work.

\section{References}

1. Lakatos G, Mészáros L, Bohátka S, Szabó S, Makádi M, et al. (1993) Application of Lemna Species in ecotoxicological studies of Heavymetals and organic biocides. Sci Total Environ 44:773-778.

2. Omar A, Balla D (2010) Potential of duckweeds for desalination and treatment of agricultural drainage water in detention ponds. 4th Conference of the European Pond Conservation Network (EPCN) Berlin (Erkner), Germany, Leibniz Centre for Agricultural Landscape Research (ZALF). Institute of Landscape Hydrology.

3. Zimmo O (2003) Nitrogen transformations and removal mechanisms in alga and duckweed waste stabilization ponds. PhD thesis, International Institute for Infrastructural, Hydraulic and Environmental Engineering, Delft, The Netherlands.

4. EPA (1996) Aquatic plant toxicity test using LemnaSpp:Tiers I and II- OPPTS 850.4400. United states Environmental protection Agency Prevention, pesticides and Toxic substances Unit, New York, USA

5. DIN (2000) Duckweed growth Inhibition test: Determination of the non poisonous effect of water constituent $s$ and waste water to duckweed, Deutsches Institut furcNormung e.V urchBeuth Verlag, Berlin 19.

6. Eberius M (2001) Assesment of Inhibition values and comprehensive analysis of biotests. Lemna Tec $\mathrm{GmbH}$, Wurselen.

7. OECD (2002) Guidelines for the testing of chemicals. Lemna Sp. Growth Inhibition Test, Draft guidline 221.

8. APHA, AWWA, WPCF (1996) Standard methods for the examination of water and wastewater analysis. American Public Health Association, Washington, DC, USA.

9. Gopal B, Chamanlal (1991) Distribution of aquatic macrophytes in polluted water bodies and their bioindicator value. Verh Int Verein Limnol 24: 2125-2129.

10. Leng RA, Stambolie JH, Bell R (1995) Duckweed- a potential high-protein feed resource for domestic animals and fish. AAAP Conf Proc Bali 7: 103-114. 
Citation: Loveson A, Sivalingam R (2013) Phytotoxicological Assessment of Two Backwater Wetlands in Kannamaly, Ernakulam Using Aquatic Macrophyte - Spirodela Polyrhiza. J Environ Anal Toxicol 3: 180. doi:10.4172/2161-0525.1000180

11. Khondker M, Nurul Islam AKM, Makhnun AD (1994) Lemna perpusilia: screening on habitat limnology. Bangladesh J Bot 23: 99-106.

12. Perfus-Barbeoch L, Leonhardt N, Vavasseur A, Forestier C (2002) Heavy meta toxicity: cadmium permeates through calcium channels and disturbs the plant water status. Plant J 32: 539-548.

13. Poschenrieder C, Barcelo J (2004) Water relations in heavy metal stressed plants. In: Prasad MNV (ed) Heavy metal stress in plants: from biomolecules to ecosystems, 2nd edn. Springer, Berlin, 249-270.

14. Song ZH, Huang GL (2001) Effect of triphenyltin on duckweed Lemna minor. Bull Environ Contam Toxicol 67: 368-375.

15. Baron M, Arellano JB, Gorge JL (1995) Copper and photosystem II: a conversional relationship. Plant Physiol 94: 174-180.

16. Lewis MA (1995) Use of freshwater plants for phytotoxicity testing: a review. Environ Pollut 87: 319-336.
17. Axtell NR, Sternberg SP, Claussen K (2003) Lead and nickel removal using Microspora and Lemna minor. Bioresour Technol 89: 41-48.

18. Hou W, Chen X, Song G, Wang Q, Chi Chang C (2007) Effects of copper and cadmium on heavy metal polluted waterbody restoration by duckweed (Lemna minor). Plant Physiol Biochem 45: 62-69.

19. Kanoun-Boulé M, Vicente JA, Nabais C, Prasad MN, Freitas H (2009) Ecophysiological tolerance of duckweeds exposed to copper. Aquat Toxicol 91 : $1-9$

20. Van Assche F, Clijsters H (1990) Effects of metals on enzyme activity in plants. Plant cell Environ 13:195-206

21. Sandalio LM, Dalurzo HC, Gómez M, Romero-Puertas MC, del Río LA (2001) Cadmium-induced changes in the growth and oxidative metabolism of pea plants. J Exp Bot 52: 2115-2126. 